\title{
Probiotics as Potent Immunomodulatory Vehicle in Poultry: A
}

\section{Short Review}

\author{
Abubakar Siddique*, Sara Azim and Muneera Anwer \\ Atta -Ur -Rahman School of Biological sciences, National University of Science and \\ technology, Islamabad, Pakistan
}

*Corresponding author: Abubakar Siddique, Atta -Ur -Rahman School of Biological

Mini Review

Volume 3 Issue 2

Received Date: October 14, 2019

Published Date: November 06, 2019 sciences, National University of Science and technology Islamabad, Pakistan, Email: Abubakars974@gmail.com

\section{Abstract}

Probiotics are the identified group of microorganisms having optimistic influence on modulating immunity of a host and modifying the gut microbiota by beneficial bacteria. Recent research suggests that immune system, microbiota of intestine and communication between epithelium cells involved in modulating the resistance. The potential gastric probiotic bacteria inhibit the pathogens by following mechanisms which includes competitive exclusion, production of toxic compounds, modulation of the immune system and competition for colonization in the gut.

Keywords: Probiotics; Modulating Immune system IgA Poultry

\section{Introduction}

Bacterial gastroenteritis infections are a significant burden to the poultry world now a days due to decrease in productivity, increased death rates, and contamination in poultry products for human consumption. Now a days due to antibiotic resistance, probiotics are subsequent approach for immunomodulation in poultry [1]. Probiotics "useful bacteria which keeps our gut environment healthy, use as microbial feed supplements which affects the host by improving intestinal balance" [2].

Major role of GIT is to absorb and digest different nutrients for conservation of normal growth, but vital function is inhibiting the entry of numerous enteric pathogens from the external sources [3].

\section{Mode of Action}

Beneficial Microbes promotes gut integrity and prevents from pathogenic diseases, through different mechanisms: Competitive exclusion, Bacterial antagonism, and Stimulation of the immune system of a host Ohimain and Ofongo, [4]. Non pathogenic bacteria produces fatty acids and bacteriocins which limits the growth of pathogenic microbes [5,6] (Figure 1).

The cohesion of the GIT plays a main role in prompting the production of poultry. The use of probiotics increases length of villi which increase the surface area and absorptive capacity and lessened the depth of intestinal crypts in poultry. Enterocytes continuously proliferating in intestinal crypts to replace the cells at the margin of vilus due to infection caused by enteric pathogens [7]. Angel, et al. [8] conducted a study, chicks were administrated with diets low in crude protein, methionine, calcium, lysine and phosphorus. Birds accompanied with the commercial probiotic product Prima Lac which reduced the negative effects of nutrient burden on bird's performance and resulted in increased nutrient maintenance of calcium, nitrogen and phosphorus. Moreover probiotics also helps in reduction of premature egg shedding in layer $[5,9,10]$. 


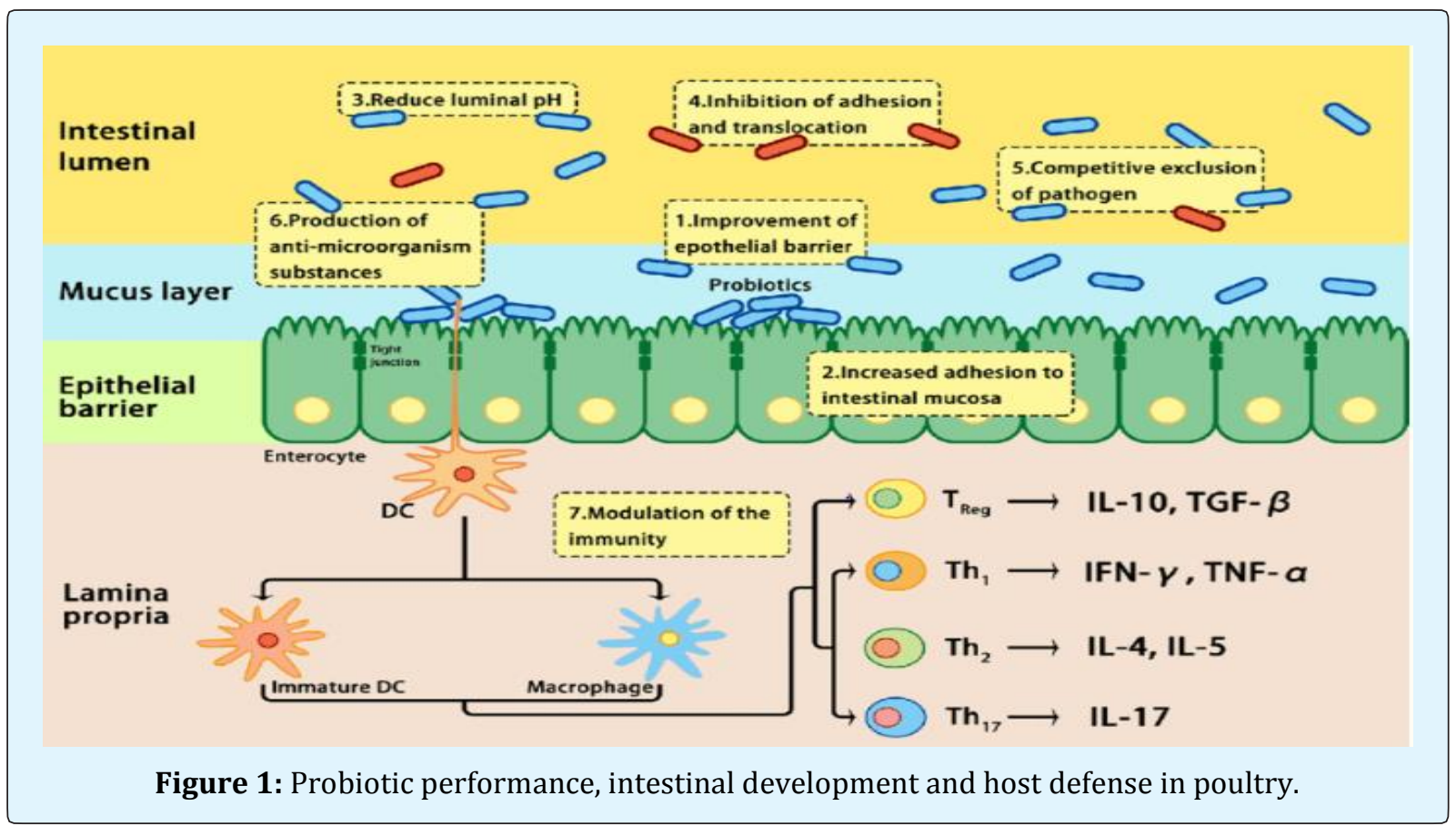

\section{Probiotics and Innate Immune Response}

Different studies have provided evidence that different strains of probiotics have ability to boost up the intestinal mucosa by commercially available product Prima Lac which stimulate the synthesis of mucin by fluctuating the bacterial population [11]. The Toll-like receptor behaves as pathogen recognition receptors which helps to identify specific bacterial components and activates a suitable immune response. According to Bai, et al. probioticsupplement with Saccharomyces cerevisiae and Lactobacillus fermentum increase the mRNA expression of toll like receptors which helps to identify the various bacterial cell components.

\section{Probiotics and Adaptive Immune Response}

Research indicates that probiotics ' importance in potentiating the chickens ' adaptive immune reaction. The increasing in the number of intestinal intraepithelial lymphocytes expressing the cell surface markers CD3, CD4 and CD8 was due to probiotics $[5,12]$. Bai, et al. mostly produced by T cells. Probiotic administration also increased serum concentrations of tetanus toxoid and alpha-toxin reactive IgG and IgM antibodies Haghighi, et al. \& Mountzouris, et al. discovered the effectiveness of antibiotic avilamycin and probiotics on humoral immune response. In comparison with the challenged control, that both treatments resulted in decreased concentrations of plasma IgA and IgG and intestinal IgA against Salmonella Enteritidis and did not differ from those of negative controls. Reducing the concentrations of antibodies could lead from increased clearance of pathogen and accelerated recovery due to their experimental treatments.

\section{Conclusion}

Probiotics supplementation have beneficial effects on poultry birds, boost up and increase the efficiency, stimulate beneficial microbes in the intestinal region, increase innate and adaptive immune reaction and counteract the adverse effects of many gastrointestinal diseases.

\section{References}

1. Borchers AT, Selmi C, Meyers FJ, Keen CL, Gershwin ME (2009) Probiotics and immunity. J Gastroenterol 44(1): 26-46.

2. Johnson BR, Klaenhammer TR (2014) Impact of genomics on the field of probiotic research historical perspectives to modern paradigms. Antonie Van Leeuwenhoek 106(1): 141-156. 
3. Hutkins RW, Krumbeck JA, Bindels LB, Cani PD, Fahey Jr, et al. (2016) Vaughan E Prebiotics why definitions matter. Current opinion in biotechnology 37: 1-7.

4. Ohimain EI, Ofongo, Ruth TS (2012) The effect of probiotic and prebiotic feed supplementation on chicken health and gut microflora a review. International Journal of Animal and Veterinary Advances 4: 135-143.

5. Pedroso AA, Batal AB, Lee MD (2016) Effect of in ovo administration of an adult derived microbiota on establishment of the intestinal microbiome in chickens. Am J Vet Res 77(5): 514-526.

6. Hume (2011) Historic perspective Prebiotics, probiotics, and other alternatives to antibiotics. Poult Sci 90(11): 2663-2669.

7. Awad WA, Bohm J, Razzazi Fazeli E, Ghareeb K, Zentek J (2006) Effect of addition of a probiotic microorganism to broiler diets contaminated with deoxynivalenol on performance and histological alterations of intestinal villi of broiler chickens. Poult Sci 85(6): 974-979.
8. Angel R, Dalloul RA, Doerr JA (2005) Performance of broiler chickens fed diets supplemented with a direct fed microbial. Poult Sci 84(8): 1222-1231.

9. Santosh H, Gupta SK, (2011) Role of probiotics in mitigating Eimeria tenella infection in broiler chicken and their effect on serum IgY levels. Indian Journal of Poultry Science 45(3): 340-344.

10. Tako E, Glahn RP, Knez M, Stangoulis JC (2014) The effect of wheat prebiotics on the gut bacterial population and iron status of iron deficient broiler chickens. Nutr J 13: 58.

11. Sanchez-Trincado JL, Gomez Perosanz M, Reche PA (2017) Fundamentals and methods for T and B cell epitope prediction. Journal of Immunology Research (2017): 2680160.

12. Noujaim JC, Filho RA, Lima ET, Okamoto AS, Amorim $\mathrm{RL}$, et al. (2008) Detection of $\mathrm{T}$ lymphocytes in intestine of broiler chicks treated with Lactobacillus spp and challenged with Salmonella enterica serovar Enteritidis. Poult Sci 87(5): 927-933. 